\title{
Contaminações textuais e discursivas na imprensa contemporânea
}

Terezinha Tagé

\section{Resumo:}

A proposta deste trabalho é a de compartilhar estudos sobre a noção de fronteira semiótica, segundo Iuri Lotman, em textos da cultura na imprensa diária, gerando novas semioses e informações em nossa atualidade, graças aos procedimentos de sistematização de signos que os constituem. A comunicação de informações se efetua no processo de contaminação entre diferentes sistemas sígnicos permitindo a apreensão de procedimentos originados em múltiplos formatos e gêneros discursivos nos diferentes sistemas de modelização. As reflexões são complementadas com a leitura de uma foto jornalística.

\section{Palavras Chave:}

Comunicação e linguagem, fronteira semiótica, discurso jornalístico, fotojornalismo, semiosfera.

\begin{abstract}
:
The purpose of this paper is to discuss the concept of semiotic boundary, according to Yuri Lotman, in culture texts in the daily press, generating new information and semiosis in our present time, thanks to the procedures of signs systems which constitute them. The communication takes place in the process of contamination between different sign systems, which allows the understanding of different procedures generated in multiple formats and genres in the different modeling systems. The reflections are complemented by a reading of a newspaper photo.
\end{abstract}

\section{Keywords:}

Communication and language, semiotic boundary, journalistic discourse, photojournalism, semiosphere

\section{O entrecruzamento de signos no jornal}

Estas reflexões são recortadas de uma pesquisa sobre processos de produção de sentido e de construção de textos e discursos nos jornais impressos diários que comunicam os significados do cotidiano da vida urbana brasileira em textos verbais e não verbais e compõem os vários formatos das mídias de diferentes épocas. Acreditamos que, ao situar os objetos de linguagem da Comunicação urbana para compreender os sentidos da vida imediata em seus desdobramentos, é possível contribuir com subsídios para estudos outras disciplinas em desdobramentos históricos e políticos.

As anotações apresentadas situam-se na parte relacionada às reflexões sobre textos onde se inscrevem os discursos jornalísticos da mídia impressa e que se caracterizam por uma permanente contaminação sígnica. Sistemas de signos verbais entrelaçam-se aos sistemas de signos visuais de modo indissociável. A leitura linear para signos discretos exige uma permanente interação com a leitura por contiguidade dos signos não discretos de fotos na diagramação de páginas.

O que é dito com palavras dilui-se ao que é dito com cores, traços imagens, espaços em branco, enfim, o grafismo da página do jornal impresso exige um mesmo movimento de leitura aproximado ao da versão 
online ou de outros produtos de comunicação construídos em telas. Impossível restringir-se a apenas um tipo de sistemas sígnico, como, por exemplo, apenas ao sistema verbal ou ao visual de fotos, infográficos e outros.

Sempre em processo de incompletude, a comunicação de informações de dizeres anteriores prepara outros dizeres ainda desconhecidos mas, atentos e prontos para registrar o inesperado em construção.

Acreditamos que os discursos dos dispositivos midiáticos podem ser considerados como monumentos do instante para apreender o registro de acontecimentos que tecem características de uma cultura, num momento histórico definido em um determinado espaço semiótico

Basta lembrar que eles reconstroem estes instantes no momento de sua instauração, apreendem os acontecimentos que se movem ininterruptamente nos dias, revelando-lhes os sentidos, para guardá-los e historicizá-los posteriormente. Por este motivo, seu estudo se faz necessário e se justifica.

O percurso dessas apreensões mergulha no imaginário social, permitindo reter os subsídios que permitirão compreender a significação dos fatos e a produção de seus múltiplos sentidos.

Os jornais impressos ou online reúnem as marcas diárias dos valores de uma cultura, selecionando e legitimando o que é hegemônico no interesse do público de leitores para ser publicado e compartilhado socialmente. Há uma escolha por parte dos responsáveis pela difusão de informações. Os princípios que regulam estes procedimentos seletivos variam no decorrer do tempo. Dependem dos discursos que lhes servem de diretrizes. Estes elementos constitutivos dos textos jornalísticos não se apagam apenas com a leitura e o consumo do que estiver escrito ou mostrado com imagens nas folhas e nas telas. O que é absorvido no imaginário social determina a interpretação dos fatos, serve de indicação para comportamentos e decisões, criando um apoio de referência que sustenta a significação gerada pelo relato dos acontecimentos. Pode ser comparado ao trabalho de um escultor e escolhido como elaboração adequada à forma esculpida em cada espécie de pedra ou outro material .

O jornal, neste caso, torna-se um monumento do instante para a história do cotidiano, um objeto de linguagem que deve ser decifrado em todos os seus elementos constitutivos e não apenas centrado no conteúdo temático. É preciso estudar o percurso dessa história do universo do imaginário social circundante, conforme a compreensão de história, aqui comparada ao exemplo escrito por Michel Foucault, adaptando ao que estamos refletindo sobre a contribuição dos textos jornalísticos em seus entrelaçamentos de sistemas sígnicos. Lemos na obra: A arqueologia do saber sobre este modo de compreender a historicidade e a função dos que se poderia nomear como "monumentos discursivos" :

“...do rumor lateral, da escrita cotidiana e tão rapidamente apagada que nunca adquire o status da obra ou que imediatamente o perde: analise das subliteraturas, dos almanaques, das revistas e dos jornais, dos sucessos fugidios, dos autores inconfessáveis. Assim definida - mas vê-se de imediato o quanto é difícil fixar-lhe limites precisos - ....no interstício dos grandes monumentos discursivos, faz aparecer o solo friável sobre o qual repousam...."(FOUCAULT:1981:157) .

Ousando estender este raciocínio para os textos da cultura de diferentes sistemas de signos, conforme Lotman (LOTMAN: 1986:77-82), entre eles os dos jornais, podemos pensar que tudo significa se desenvolvermos o processo de leitura da contaminação dos sentidos produzidos pelo grafismo das páginas, incluindo as fotografias nelas inseridas.

Todos os signos presentes não podem ser apenas devorados por uma leitura passageira e conteudística. Seria uma apreensão parcial e mutilada dos sentidos produzidos na mensagem. A colocação de uma 
fotografia, a legenda, o seu tamanho e lugar no espaço noticioso, o tamanho das letras, a correspondência ou não entre a manchete e o texto, a perspectiva destacada durante o processo de edição, as cores, as formas, os espaços em branco, podem gerar as mais diversas leituras e repercussões.

O que nos é permitido saber sobre o mundo e sobre as coisas que nele existem, depende do que foi escolhido em cada dia para ser traduzido em informação e acabou chegando até nós.

Há, porém um aspecto em todo este caminho que é preciso levar em conta. A seleção do que recebemos como "fatos do dia" é tão importante quanto a própria seleção do modo pelo qual ela foi reportada nas folhas ou nas telas. Se tudo significa, então, a cada leitura de jornal estamos diante de um monumento o cotidiano, que precisa ser absorvido por inteiro. Não é válido captar apenas uma parte como olhar uma estátua sem conhecer seu pedestal de base e sem interagir com a inscrição que lhe acrescenta sentidos, sem compreender a semiosfera que os legitima.

A leitura de jornais passa a ser uma experiência de jogo com as linguagens. Um processo de seleção diária de sentidos para preservar na memória e não mais a coleção aleatória de informações acumuladas e digeridas ligeiramente, comentadas ao sabor do vento pela superficialidade de conversas rotineiras. É preciso captar o traço eterno na fugacidade aparente. Neles estão guardados os sentidos sociais dos fatos que construímos socialmente ou a sua historicidade.

O discurso jornalístico é solidário como tantos outros. Seus recursos técnicos específicos podem estar em diferentes suportes de comunicação além dos jornais. Do mesmo modo, nas páginas ou telas dos jornais encontramos recursos de diferentes ordens, provenientes de outros dispositivos, como o livro, a teledramaturgia, o noticiário televisivo, o cinema, a propaganda e a publicidade, os catálogos fotográficos, entre as várias possibilidades que surgem a cada dia, graças ao auxílio das tecnologias contemporâneas.

Diante de tais evidências, quando perguntamos qual a natureza do jornalismo em nossos dias, para ter um grau mínimo de orientação, deparamo-nos com uma infinidade de perspectivas, sem nenhum ponto mais consistente que nos permita chegar a uma reposta definitiva.

.No que se refere ao jornalismo chamado "impresso", ouvimos palavras (sempre elas) nem um pouco consoladoras :"jornalismo de espetáculo"," investigativo"," ensaístico","documentário"," literário"," cultural","político"," econômico", em versões de papel, como os periódicos da imprensa diária. Existem também os livros-contos- romances -reportagem, documentários e reportagens-ensaios. Tudo isso em papel ou em dispositivos eletrônicos, telas de TV, CDs e outras possibilidades.

São simplesmente versões da vida imediata na materialidade dos múltiplos sistemas de signos

São nomeações fragmentadas, um verdadeiro esquartejamento dos sentidos atribuídos à leitura e interpretação da vida social, que procuram classificar tentando esclarecer estes modos de reportar a gesta humana e urbana, informando sobre as suas motivações essenciais e universais (globais?).

Essas classificações indicam as posturas dos executores desta prática de comunicação social quando realizam seus trabalhos ou efetuam a leitura conteudística de seus resultados, mas nem sempre contemplam as características da matéria simbólica com que são reconstruídas as ideias, os pensamentos, os sentimentos, as emoções tanto no papel quanto na tela ou algum outro suporte. Não é comum encontrar referências ao percurso dos elementos utilizados para a reconstituição do mundo exterior na página impressa. A produção editorial, os processos de seleção de pautas e distribuição de palavras, imagens, grafismos, tudo o que, de modo dominante organiza a forma pela qual se reporta a vida, em diferentes 
matizes, movendo-a outra vez, construindo a sua comunicação, inserido-a no mais íntimo pensamento do leitor, em geral deve ser objeto de atenção de interessados nos estudos desses fenômenos da Comunicação.

Quais seriam as razões desta recepção equivocada? Por que a insistência na leitura de superfície? Como auxiliar no exercício de desdobramento e interação entre as várias possibilidades de leitura que os jornais permitem em seus múltiplos suportes? Qual a natureza destes monumentos em transformação?

\section{Os textos da cultura nas mídias contemporâneas}

Pensar a Comunicação em suas manifestações sociais a partir dos textos elaborados nas produções midiáticas em todos os tempos históricos é um desafio para o pesquisador desta área, embora seja uma abordagem legítima para compreender este fenômeno de um modo coerente com a sua natureza e com suas demandas no mundo contemporâneo.

Por este motivo, a noção de texto, segundo o pensador e semioticista Iúri Lotman, em um dos segmentos da Semiótica da Cultura, justifica-se como um apoio pertinente, entre muitos outros, para mergulhar neste universo tão diversificado, maleável, paradoxal, mas, sobretudo e por isso mesmo, condizente com o movimento da vida social imediata de cada época. Ajuda-nos a compreender nossa condição de humanos quando manifestada em produções midiáticas contemporâneas ou não.

Para Lotman, desde seus primeiros estudos da década de 70, o texto sempre foi considerado como todo sistema de signos verbais ou não verbais inter-relacionados para comunicar uma mensagem. Seu significado é constituído na correlação

“(...) com otros sistemas de significado más amplios, com otros textos, com otros códigos, com outras normas presentes em toda cultura, em toda sociedad. Por tanto, comprender un texto(artístico o non) es compreender no solo las relaciones intratextuales, sino también las relaciones extratextuales y las que surgen de confrontar éstas con aquéllas”. (SANCHES, 1996, 258.)

Este apoio teórico, quando escolhido pelos pesquisadores da Comunicação que abraçaram a causa de estudar o processo de constituição de significados em permanente interação entre sistemas de signos e formatos nos textos da cultura e, por extensão, nos textos da cultura nas mídias e não das mídias, remetenos à noção de semiosfera e de fronteira.

Antes de continuar, é preciso esclarecer no corpo deste escrito, a diferença de posicionamento entre estas duas possibilidades de estudo.

A primeira (textos da cultura nas mídias) prioriza os textos da cultura de espaços semióticos diferentes quando passam a pertencer à semiosfera delimitada onde se encontra o objeto e a mídia recortados para o estudo do pesquisador.

Como exemplo, uma peça de teatro transformada em telenovela, Ciranda de Pedra, adaptada para versão teledramatúrgica, um romance como Lavoura Arcaica, de Raduan Nassar, traduzido semioticamente para o filme homônimo de Luiz Fernando Carvalho, atribuindo ao sistema sígnico verbal uma dimensão sonora de teor personificado, tornando-o quase "personagem", tal a sua importância; uma crônica de um escritor de ficção publicada em jornal diário, onde está reproduzida uma parte de outro texto da cultura 
como um trecho de romance ou uma carta particular. Outro exemplo, considerando o romance como mídia diferenciada escrita em um tempo distante, está na obra: Ligações Perigosas, de Pierre Chordelos de Laclos (1741-1803), composto por um diálogo de cartas e que sugeriu outros textos em diferentes épocas.

Estes textos preservam de algum modo o próprio gênero (1) ou o formato (2) ou os elementos componentes de base com poucas variações estruturais e adaptações exigidas pelas linguagens do universo midiático em que se encontram, criando outros produtos híbridos e outros gêneros de difícil classificação entre as que conhecemos.

Estes textos midiáticos passam a pertencer à cultura e interagem nas mídias tradicionais de comunicação ou nas diferenciadas, integrando-se a elas para gerar outras semioses, preservar sentidos ou resgatá-los. Ao mesmo tempo, conservam traços de seus atributos originais. Alguns podem ser lidos e interpretados de modo autônomo e também podem integrar-se a outras semiosferas. Carregam as marcas de diferentes gêneros discursivos e de diferentes formatos que foram adquirindo sem perder sua autonomia.

A segunda (textos das mídias) refere-se aos textos diretamente criados para as mídias contemporâneas ou não, mesmo que tragam em sua composição recursos e elementos estruturais e intertextuais provenientes de outros gêneros e formatos segundo as classificações tradicionalmente aceitas. Por exemplo, as telenovelas concebidas como tal e que inserem discursos, estratégias de abordagens do jornalismo, os jornais que reiteram grafismos e recursos infográficos retomados de histórias em quadrinhos ou dos enquadramentos televisivos ou cinematográficos e inúmeras outras possibilidades de diálogo textual e discursivo em relação às suas estruturas composicionais e também à temática destacada pelo objeto em estudo.

Chegamos até a pensar que o estudo dos textos midiáticos supõe o estabelecimento de um permanente e natural diálogo entre os elementos constitutivos de seus formatos e gêneros.

Estas reflexões levaram-nos às seguintes questões: seriam os textos midiáticos da Cultura espaços semióticos criados na fronteira entre diferentes semiosferas, entre seus diferentes níveis, entre gêneros discursivos, entre gêneros textuais, entre novos formatos dos meios emergentes e alternativos como característica de sua própria natureza?

\section{A noção de fronteira e os textos jornalísticos diferenciados}

Quando falamos em fronteira é preciso pensar na noção de semiosfera. Ela foi introduzida por Iúri Lotman ao perceber que os sistemas de signos não existem isolados. Tornam-se vivos e adquirem sentido quando estão:

(...) submergidos en um continuum semiótico, completamente ocupado por formaciones semióticas de diversos tipos y que se hallan em diversos niveles de organización. A ese continuum, por analogía con el concepto de biosfera introduzido por Vernadski, lo llamamos de semiosfera...(LOTMAN,1996: 22)

Assim como a biosfera de Vernadski é um mecanismo cósmico que tem um lugar definido na estrutura do planeta, envolvendo completamente toda a matéria viva, transformando-a e conservando-a, a semiosfera é um espaço pleno de signos e abstrato, fechado, dentro do qual é possível a geração e transformação do sentido produzido na materialidade sígnica que nos envolve. Uma camada protetora de signos que são 
modelizados em textos no "planeta da Cultura" para permitir a Comunicação. É compreendida como um lugar onde se dá o funcionamento de todo sistema de signos. Nele os processos comunicativos tornam-se possíveis e as informações novas são produzidas.

Entre os estudos desenvolvidos pelo pensador estoniano da Escola de Tártu e divulgados no ocidente, citamos como exemplo clássico Universe of the Mind: a Semiotic Theory of Culture (LOTMAN, 1990), organizados por Ann Sukman, e os três volumes da coletânea de artigos La Semiosfera (LOTMAN, 1996, 1998: 2000), publicados por Desidério Navarro nos quais as duas noções referidas, semiosfera e fronteira, surgem de maneira mais amadurecida.

Sempre em traduções para a língua inglesa, italiana, francesa, espanhola, luso-portuguesa e outras que até hoje estão nas bibliotecas particulares de interessados e nas de raras universidades brasileiras ou em poucas livrarias especializadas. Esta condição para quem não conhece a língua russa dificultou o acesso à leitura dessa obras e é causa de equívocos e polêmicas quando a preocupação é a de encontrar a correspondência terminológica precisa e a sua compreensão nas fontes, gerando preconceitos e recusas quanto à legitimidade e validade destas pesquisas na área da Comunicação e outras.

Estas reflexões apóiam-se na leitura da segunda parte da obra citada (LOTMAN, 1990), no capítulo 9, Lotman nos apresenta a importância da noção de fronteira. .

Inicia sua exposição de idéias, demonstrando que a semiosfera tem assimetrias e paradoxos porque contém oposições entre seus textos componentes e esta noção de fronteira é um de seus mecanismos característicos para articulá-las.

Ele enfatiza que a fronteira é uma noção ambivalente porque ao mesmo tempo une e separa diferentes semiosferas. Não é um limite que separa dois espaços diferentes, mas é um espaço de intersecção onde se dá a passagem e a integração de elementos de espaços semióticos opostos. Pode ser relacionada com as traduções intersemióticas entre sistemas de signos, entre formatos ou entre gêneros diferentes do ponto de vista formal ou entre culturas com valores éticos e estéticos opostos. O processo de estabelecimento de relações, a intersecção entre diferenças gerando outros produtos semióticos que contenham elementos que pertencem às duas semiosferas diferentes em qualquer um de seus níveis internos é o que importa.

Vivemos imersos em um mundo que nos toca e afeta com um plano simbólico com o qual necessitamos nos comunicar. Alguns objetos deste plano podem ter um significado para nós e outros não. Para compreendermos o significado de cada objeto e estabelecermos uma comunicação com o mesmo é preciso que ele tome forma, que se modelize, que seja semiotizado, isto é, organizado em um ou mais sistema de signos, em textos que só pertencerão à cultura e tiverem história e memória na semiosfera que os anima. Enquanto não tiverem estas características são apenas não textos.

Ao ser semiotizado, um conjunto de signos torna-se texto modelizado, permite que o mundo seja significativo. É o texto que cria a possibilidade de significar para as linguagens e não o contrário. Ele desencadeia um processo de geração de mensagens, de semiose, como condição de vida comunicativa.

Por este motivo, a cultura pode ser considerada como um conjunto de textos em diferentes semiosferas que se inter-relacionam. No espaço interno das mesmas, que é percorrido por diferentes linguagens e níveis que a atravessam, há subsemiosferas interligadas e ao mesmo tempo interseccionadas pelos mecanismos das fronteiras.

Um exemplo pode ser encontrado quando encontramos textos de um gênero dialogando com outro ou 
interagindo no espaço semiótico alheio.

Surge uma nova situação no processo de constituição textual porque os princípios de um gênero de texto acabam sendo reestruturados pelas condições de organização de outro gênero, "and at same times preseves a memory of its other system of encoding". (LOTMAN, 1990: 137)

\section{Gêneros de fronteira na produção textual da imprensa brasileira: leitura de uma foto jornalística}

As reportagens jornalísticas publicadas em jornais diários de grande circulação tornam-se com o passar do tempo textos da cultura do ponto de vista semiótico porque guardam significados de uma determinada época e geram novos significados em outras, dependendo do modo como foram modelizadas.

Para exemplificar este fenômeno, apresentamos subsídios iniciais para a leitura de uma foto jornalística apenas como um pequeno exemplo.

Trata-se da foto da página inicial do Caderno "Aliás, a semana em revista", encartado no Jornal O Estado de S. Paulo do dia 26 de outubro de 2008.

O tema central apresenta uma sequência de fotos sobre o seqüestro e assassinato da jovem Eloá Cristina Pimentel, praticado pelo ex-namorado e seqüestrador Lindemberg Alves. Este acontecimento motivou inúmeras reações no público em geral e mobilizou a imprensa para a criação de diferentes produções textuais. Foram acionados recursos específicos de processo de produção de diferentes tipos de mídia que passaram atuar e a convergir para comunicar os passos do acontecimento. $\mathrm{O}$ objetivo era o de gerar sentidos em diferentes níveis das semiosferas que configuraram as sensibilidades emergentes.

O enunciado inicial da página é continuado por seis quadros e continuado por comentários e pode ser considerado como um registro resumido em suas principais marcas Uma sequência de uma narrativa indicial e sintética do acontecimento elaborada em diferentes sistemas sígnicos que se contaminam para gerar os sentidos da comunicação do acontecimento. Uma mistura de discurso verbal, história em quadrinhos, fotojornalismo, crônica, telenovela, filme de terror, reportagem policial e muito outros modos tradicionais de classificação que se diluem diante do leitor.

No primeiro quadro, em uma foto da imprensa já publicada em reportagens anteriores é na qual é retomado o bilhete escrito pelos amigos da vítima pedindo sua liberdade ao sequestrador com o enunciado: 'Liberdade, Eloá" No segundo, a vítima transportada pelos bombeiros e pela polícia , depois de atingida fatalmente. No terceiro uma cena do velório. No quarto quadro, um grupo de jovens amigos de cabeça baixa e consternados pelo impacto sofrido como metáfora da reação do público em geral. No quinto, uma foto reportagem em que aparece o assassino sendo encaminhado para a prisão, obtida de outra mídia, a televisão, uma cena congelada de uma reportagem em vídeo da TV Record e reproduzida com um enunciado por ele emitido com se fosse um personagem: "Eu tava pensando em curtir cada minuto com ela".O enunciado verbal passa a fazer parte do conjunto da imagem e a integrá-la Neste quadro, retomada a fala reproduzida sobre a cabeça de Lindemberg, como uma legenda sobre um personagem de uma "ficção-real", porque a forma da ficção integra a realidade comunicada. No último quadro , a foto da amiga e co-participante do episódio, que sorri apesar da marca do ferimento na face como um final infeliz. 

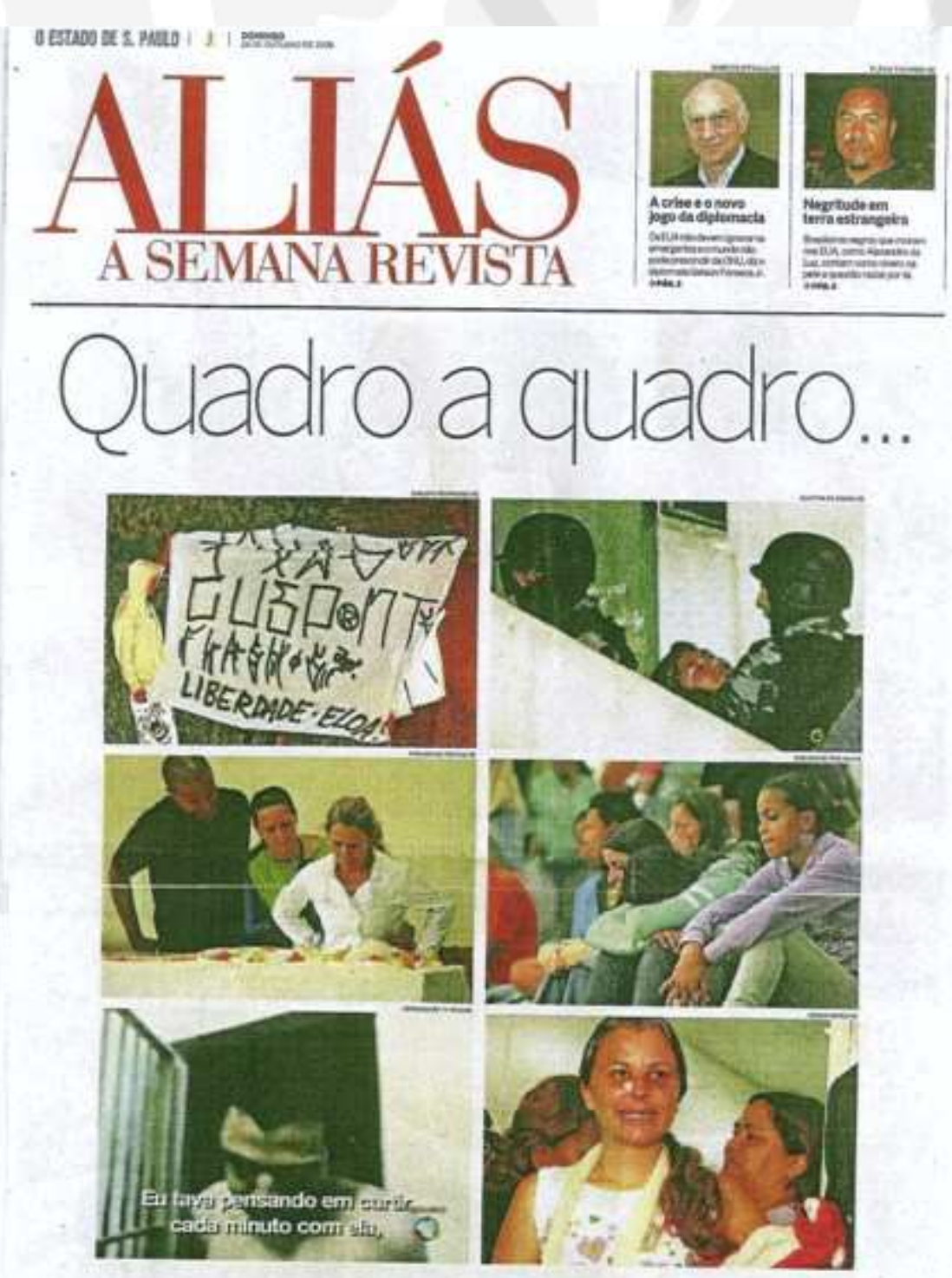

...como num filme ou reality show. O desenrolar e desfecho do cárcere privado em que morreu a jovem Eloá Cristina Pimentel "mobilizou a imprensa, atiçou a guerra da audilencla, alimentou a caktarse, "Essa dinâmica do espetáculo não consegue evitar . os holofiotes", diz o jornalista e professor de ética Eugênio Bucci. "Em casos assim, o desafio é informar sem mistuificar." Para o sociólogo José de Souza Martins, os destinos desencontrados, embora tão próximos, do seqüestrador Lindemberg Alves e sua vî́ima revelam a crise da nossa modemidade inviável.

O Início da mensagem "Quadro a Quadro...” seguida da sequência de quadros é continuada com três pontos indicativos desta continuidade da narrativa do texto visual das fotos pelo texto verbal "...como num filme ou reality show. O desenrolar do desfecho do cárcere privado em que morreu a jovem Eloá Cristina Pimentel mobilizou a imprensa, atiçou a guerra da audiência, alimentou a catarse”.

Em seguida, são incluídas análises de comentaristas com falas autorizadas de diferentes campos do saber social:

"Esta dinâmica do espetáculo não consegue evitar os holofotes", diz o jornalista e professor de ética Eugênio Bucci. "Em casos assim, o desafio é informarr sem mistificar". 
Para o sociólogo José de Soiuza Martins, os destinos desencontrados, embora tão próximos, do sequestrador Lindemberg Alves e sua vítima revelam a crise da nossa modernidade inviável.

Desse modo, é possível observar a sequência dos elementos constitutivos da mensagem desta página, construídas por contaminações de sistemas sígnicos provenientes da narrativa na reportagem jornalística, das histórias em quadrinhos, do cinema, da teledramaturgia, das antigas fotonovelas. Em seguida, surgem enunciados de falas autorizadas de cientistas sociais e docentes universitários.

Neste entrecruzamento de semiosferas em suas delimitações atravessadas, surgem novos espaços semióticos das fronteiras que, segundo Lotman não os separam, mas, ao contrário, criam outros, gerando múltiplos sentidos.

Para Lotman: "Paradoxically, the internal space of a semiosphere is at the same time unequal yet unified, asymmetrical yet uniform." (LOTMAN, 1990: 131)

As produções são sistemas sígnicos inter-relacionados na intersecção de assimetrias e oposições e como gêneros de fronteira. Apresentam em seus elementos constitutivos características de dois formatos textuais que se cruzam e, como conseqüência, desencadeiam um processo de interação entre seus gêneros discursivos, e entre diferentes códigos, possibilitando uma espécie de diálogo de sistemas sígnicos.

Este procedimento se dá tanto do ponto de vista estrutural quanto semântico. O mecanismo da fronteira entre textos da mesma semiosfera permite que o espaço semiótico do jornalismo invada outros como a forma do cinema, da ficção e da reportagem televisiva, dos procedimentos da histórias em quadrinhos e vice-versa.

Estes processos de atravessamento entre gêneros discursivos e textuais permitem um diálogo entre formatos e os sentidos por eles gerados.

Passam a construir memória e história graças aos processos de sistematização de signos que as constituem e podem ser interpretados em espaços semióticos diversificados.

Nelas é possível recapturar as marcas de uma cultura tanto no espaço midiático quanto em obras de arte, mitos, rituais e outros objetos de estudo porque passam a fazer parte da memória textual na cultura.

Somente no mecanismo da fronteira a significação da mensagem é comunicada plenamente.

Por este motivo, talvez, seja possível pensar a necessidade desses estudos sobre fronteiras semióticas como essenciais na Comunicação.

\section{Bibliografia:}

FOUCAULT, Michel.A arqueologia do saber. Trad. Luiz Felipe Baeta Neves, Rio de Janeiro, ForenseUniversitária. 1987.

LOTMAN, I. (1990) The notion of boundary, em .Universe of the mind: a semiotic theory of the culture, 
Indiana University Press, trad. Ann Shukman, introdução de Umberto Eco, pp.131 a 142.

(1986) .La Semiosfera I: semiótica de la cultura y del texto, trad.de Desidério Navarro, Madrid, Ediciones Cátedra.

(1998) .La Semiosfera II: Semiótica de la cultura, del texto de la conducta y del espacio, trad.de Desidério Navarro, Madrid, Ediciones Cátedra.

(2000). .La Semiosfera III: Semiótica de las artes y de la cultura, trad.de Desidério

Navarro, Madrid, Ediciones Cátedra.

SANCHES, (1986) Iuri Mijáilovich Lotman (1922-1993): una biografia intelectual, em: .La Semiosfera I: semiótica de la cultura y del texto, trad.de Desidério Navarro, Madrid, Ediciones Cátedra, pp. 249 a 263.

\section{Notas:}

(1) Estamos nos referindo ao conceito de gênero do discurso como “(...) todo conjunto de enunciados relativamente estáveis... em uma esfera de atividade humana”, conforme Bakhtin.

(2) Consideramos formato as formas dos objetos estudados enquanto dispositivos midiáticos em mídias contemporâneas ou não, emergentes ou diferenciadas.

\section{Mini Currículo :}

Doutora em Ciências da Comunicação pela ECA/USP, Mestre em Letras (Literatura Brasileira) pela FFLCH/USP. Docente e pesquisadora no Departamento de Jornalismo e Editoração e no Programa de Pós-Graduação em Ciências da Comunicação da ECA. 